\title{
Arabic-speaking migrants' attitudes, opinions, preferences and past experiences concerning the use of interpreters in healthcare: a postal cross-sectional survey
}

\author{
Emina Hadziabdic ${ }^{*}$, Björn Albin and Katarina Hjelm
}

\begin{abstract}
Background: Good communication is an important prerequisite for equal treatment in a healthcare encounter. One way to overcome language barriers when patients and healthcare staff do not share the same language is to use a professional interpreter. Few previous studies have been found investigating the use of interpreters, and just one previous study from the perspective of European migrants, which showed that they perceived interpreters as a communication aid and a guide in the healthcare system as regards information and practical matters. No previous study has gathered quantitative information to focus on non-European migrants' attitudes to the use of interpreters in healthcare encounters. Thus, the aim of this study was to investigate Arabic-speaking individuals' attitudes, opinions, preferences and past experiences concerning the use of interpreters in healthcare in order to: (i) understand how persons' expectations and concerns regarding interpreters may vary, both within and across cultural/linguistic populations; (ii) understand the consequences of diverse opinions/expectations for planning responsive services; and (iii) confirm findings from previous qualitative studies.
\end{abstract}

Method: A postal cross-sectional study using a structured self-administered 51-item questionnaire was used to describe and document aspects of Arabic-speaking individuals' attitudes to the use of interpreters in healthcare. The sample of 53 Arabic-speaking migrants was recruited from three different places. Participants were mostly born in Iraq and had a high level of education and were almost equally divided between genders. Data were analysed with descriptive statistics.

Results: The main findings were that most of the participants perceived the interpreter's role as being a communication aid and a practical aid, interpreting literally and objectively. Trust in the professional interpreter was related to qualification as an interpreter and personal contact with face-to-face interaction. The qualities of the desired professional interpreter were: a good knowledge of languages and medical terminology, translation ability, and sharing the same origin, dialect and gender as the patient.

Conclusion: This study confirmed previous qualitative findings from European migrant groups with a different cultural and linguistic background. The study supports the importance of planning a good interpretation situation in accordance with individuals' desire, irrespective of the migrant's linguistic and cultural background, and using interpreters who interpret literally and objectively, who are highly trained with language skills in medical terminology, and with a professional attitude to promote communication, thus increasing cost-effective, high-quality individualized healthcare.

Keywords: Arabic-speaking migrants, Communication, Cross-sectional survey, Healthcare encounter, Structured self-administered questionnaire, Use of interpreters

\footnotetext{
* Correspondence: emina.hadziabdic@Inu.se

School of Health and Caring Sciences, Faculty of Health and Life Sciences, Linnaeus University, SE-351 95, Växjö, Sweden
}

\section{Biomed Central}

(c) 2014 Hadziabdic et al.; licensee BioMed Central Ltd. This is an Open Access article distributed under the terms of the Creative Commons Attribution License (http://creativecommons.org/licenses/by/2.0), which permits unrestricted use, distribution, and reproduction in any medium, provided the original work is properly credited. 


\section{Background}

Individualized and holistic healthcare is based on ideals of equal value and fair and equal treatment for all members of society [1]. One important prerequisite for equal treatment in a healthcare encounter between healthcare professionals and migrants is clear communication [2,3]. Unclear communication is associated with disparate healthcare access and healthcare outcomes for migrants [4,5]. One way to overcome barriers in communication between healthcare professionals and migrants is to use professional interpreters [6-8].

To our knowledge, no previous study has focused on non-European migrants' attitudes, opinions, preferences and past experiences concerning the use of interpreters in healthcare encounters based on quantitative information. However, there are previous qualitative studies in Sweden examining how Bosnian/Croatian/Serbian-speaking migrants [9], healthcare staff [10] and family members [11] perceive the use of interpreters in healthcare. The mixture of immigration to Sweden has changed in recent years, with an increasing number of people from outside Europe [12]. Today the largest group coming to Sweden are Arabic-speaking migrants from the Middle East [13]. Due to these changes, it is important to investigate a larger population and a different migrant group with a different cultural and language background in order to: (i) understand how persons' expectations and concerns regarding interpreters may vary, both within and across cultural/linguistic populations; (ii) understand the consequences of diverse opinions/expectations for planning responsive services; (iii) confirm findings from previous qualitative studies. However, migrants in Sweden represent 171 different nationalities and constitute a very heterogeneous group, with Arabic-speaking migrants as the largest group of migrants coming to Sweden in recent years, a trend that is expected to continue [14].

A literature search showed that European migrants speaking the Bosnian/Croatian/Serbian languages and living in Sweden perceived interpreters as a communication aid and a guide to the healthcare system as regards information and practical issues [9]. Furthermore, they desired an interpreter with good skills in medical terminology and language, and with a professional attitude in personal contact through face-to-face interaction. Another investigation [15] focusing on Bosnian/Croatian/ Serbian and Russian refugees in Ireland showed that use of informal interpreters could be experienced as inadequate and problematic because patients were often left worried, frustrated with experiences of error and misdiagnosis and unsure about following doctors' advice for treatment at the end of their consultation. Particularly migrants of Asian origin in the UK expected that a good interpreter should empathize with them and understand and relate to their situation [16]. Additionally, patients preferred to use family members as interpreters [16,17]. Differences in cultural background and lack of confidence in interpreters were seen as problems for cross-cultural communication for Kurdish war-wounded refugees in Sweden [18]. In summary, there is no knowledge of nonEuropean, Arabic-speaking individuals' attitudes, opinions, preferences and past experiences concerning the use of interpreters in healthcare to assist in promoting communication for individuals who use interpreters in order to develop an affordable and accessible system of healthcare encounters. Thus, the aim of this study was to investigate Arabic-speaking individuals' attitudes, opinions, preferences and past experiences concerning the use of interpreters in healthcare.

\section{Method}

\section{Design}

A postal cross-sectional survey using a structured selfadministered questionnaire [19] was used to describe and document aspects of Arabic-speaking individuals' attitudes, opinions, preferences and past experiences concerning the use of interpreters in healthcare.

\section{Setting}

Participants were recruited from three different cities in a county in Sweden, where 13.5\% of the population was born abroad [20] and where interpreters are frequently use in diverse healthcare services.

People who have communication barriers are entitled to access to an interpreter in all contacts with healthcare service according to Swedish law [21] (for more details see [22]. In the studied area the responsibility for arranging an interpreter in a healthcare encounter lies with the healthcare service. The interpreter service agencies are often run by private enterprises outside health care. National guidelines for professional interpreters include literally translating, being neutral, ensuring confidentiality and not making any other statements unrelated to the situation [22].

\section{Participants and procedure}

Criteria for inclusion in the study were Arabic-speaking adults (aged over 18) participants who use interpreters in healthcare, differing in gender, age, educational level and length of residence in Sweden.

To come into contact with participants the principal investigator contacted representatives of adult education facilities for immigrants by telephone. The representatives were requested to invite Arabic-speaking persons with different backgrounds living in Sweden to participate in an information meeting. A time was set for meetings when information (verbal and written) was given by the principal investigator (EH) about the aim of the study, focusing on the use of an interpreter in healthcare 
encounters from their perspective, about the implementation of the study and the ethical considerations. Written information and a questionnaire together with a prepaid envelope were given to voluntary participants so they could answer when appropriate. The questionnaire in the prepaid envelope was to be returned to the principal investigator. The principal investigator's contact details were included in case the participants had any questions. Participants did not have to write their names if they did not want to.

Ninety questionnaires were distributed between December 2011 and February 2012 at three different adult education facilities for immigrants. In total 53 persons returned the questionnaire, giving a response rate of $52 \%$ (see Table 1). All were refugees, born mostly in Iraq, with a high level of education.

\section{Data collection}

A 51-item questionnaire with some additional background data questions was developed based on four previous qualitative studies $[10,11,23,24]$ concerning the use of interpreters in healthcare to ensure content validity [19]. When formulating questions, the results from the previous qualitative studies were organized into three different areas: questions related to the individuals' attitudes to the use of interpreters as a communication aid in healthcare (21 items); questions related to the individuals' attitudes to the professional and personal qualities

\section{Table 1 Characteristics of the study population}

\begin{tabular}{ll}
\hline Variable & $\begin{array}{l}\text { Arabic-speaking } \\
\text { individuals } \mathbf{N}=\mathbf{5 3})\end{array}$ \\
\hline Gender (n) & 24 \\
Male & 23 \\
Female & 6 \\
Missing & \\
Age (years) & 15 \\
18-28 years & 13 \\
29-39 years & 15 \\
40-49 years & 7 \\
50-59 years & 3 \\
Missing & $9(1-11$ years) \\
Length of residence in Sweden (years) & 5 \\
Missing & \\
Educational & \\
Primary school & 5 \\
Secondary school & 16 \\
University $\leq 2$ years & 12 \\
University $\geq 2$ years & 8 \\
Missing information & 12 \\
\hline
\end{tabular}

*Values are median (range). of an interpreter in healthcare (19 items); and questions related to the individuals' attitudes to modes of interpretation and the types of interpreter in healthcare (11 items).

The questionnaire was first written in Swedish and then translated into Arabic by a professional translator and then back into Swedish by another professional translator [25]. In order to avoid communication misunderstandings, the questionnaire was pilot-tested by 20 Arabic-speaking persons. They found the questions in the questionnaire clear, concise and easy to answer. Thus, no changes were made and those respondents were included in the study.

Arabic-speaking persons responded to statements in the questionnaire by giving a rating on an ordinal 4-point Likert scale, ranging from 1 (strongly disagree) to 4 (strongly agree), i.e. the higher the values, the stronger the dimension of agreement. The questionnaire included three areas of perceiving the use of interpreters in healthcare: communication aid (21 items); the professional and personal qualities of an interpreter (19 items); modes of interpretation, and the type of interpreters (11 items). The data is presented as selected dichotomous variables, by summing responses strongly disagree and disagree respective strongly agree and agree in order to report as dichotomous variables as possible to show either a positive or negative view, since the participants mostly responded on only two values respectively by either disagreeing or agreeing.

\section{Data analysis}

Descriptive statistics, in terms of frequencies and percentages, were used to analyse [19] the three areas of the use of interpreters with the help of SPSS version 20 (SPSS Inc, Chicago, IL, US). The 35 variables were chosen for presentation in the table in order to make the table more manageable and easy to read [26]. However, responses from all included 51 variables are reported in the results section. Thus, nothing has been omitted.

\section{Ethical considerations}

The study followed Swedish law concerning the regulation of ethics in research involving humans [27] and has been conducted in accordance with established ethical principles for human clinical research in the guidelines stated in the World Medical Association's Declaration of Helsinki [28]. Participants were given written information about the study, assured of confidentiality and the right to withdraw. To preserve the confidentiality of the participants' data, the questionnaires were anonymous and coded by number. The analysis and presentation of the data was done on group level and in a way that concealed the participants' identity. All the collected data were stored in a locked space accessed only by the principal investigator $[27,28]$. The procedure was in accordance with Swedish law [27] and approval by an official 
research ethics committee was not required as the research study posed no physical or mental risk to the participants and did not treat participants' personal data.

\section{Results}

\section{Communication aid}

Almost all of the participants perceived an interpreter as a communication aid when people could not speak the same language (94\%), translate information (90\%) so that they could understand and make themselves understood (91\%) (see Table 2). With few exceptions (96\%) the participants perceived that, besides being a communication aid, the interpreter had an important role in helping them to find the right way to and within the healthcare system, as more than half of participants (67\%) were unable to read signs.

Three quarters of the participants (75\%) thought that the interpreter should interpret literally without any value judgments being made.

Little more than a quarter of individuals (28\%) perceived that talking through an interpreter gave a feeling of insecurity. Nearly half of participants (43\%) perceived the use of an interpreter as a form of physical handicap. Furthermore, for more than half of participants (57\%) the interpreters could decrease the intimacy in the relationship between individuals and healthcare staff; almost one third (30\%) thought that the presence of an interpreter made them forget to say some things; and almost one third (29\%) felt insecure when talking through interpreters, and almost half of participants (40\%) concerning the sensitive matters especially. More than half of the participants $(60 \%)$ (19 men and 6 women) felt insecure as to whether or not interpreters were able to translate what they said literally. Over three quarters (85\%) also felt uncertain about the interpreter's respect for confidentiality. Almost three quarters of the participants $(72 \%)$ expressed that room where interpretation occurs are significant. The majority of the respondents (83\%) felt that a secluded room for an interpretation situation was an important factor to be able to understand and feel safe. However, many of the participants $(68 \%)$ did not think that continuous use of the same interpreter was important.

It was found that healthcare staff booked interpreters for the majority of respondents $(87 \%)$ However, little more than half of participants (53\%) had experienced situations in healthcare when no interpreter had turned up for the appointed consultation. Participants thought that it was important that healthcare staff book an interpreter for every consultation (70\%), with the possibility of replacing a particular interpreter if patients did not feel trust (98\%).

\section{The professional and personal qualities of an interpreter} Most participants (94\%) thought that feeling trust in an interpreter is essential for whether they openly talk about their health condition in a healthcare encounter. The professional interpreter's language skill in both languages, Swedish and Arabic, was rated as unimportant for almost all respondents (96\%) (see Table 3). The professional interpreter's religion was likewise of no importance

Table 2 Questions concerning Arabic-speaking individuals' attitudes to the use of interpreters as a communication aid in healthcare

\begin{tabular}{|c|c|c|c|c|}
\hline Variable & $\mathbf{N}$ & $\begin{array}{l}\text { Agreed } \\
\text { N (\%) }\end{array}$ & $\begin{array}{l}\text { Disagree } \\
\mathrm{N}(\%)\end{array}$ & $\begin{array}{l}\text { Mean } \\
\pm \text { Sd. }\end{array}$ \\
\hline $\begin{array}{l}\text { It is important that the interpreter helps you to find the way within health care to different } \\
\text { consultations because it is difficult for me to read signs in English }\end{array}$ & 53 & $51(96 \%)$ & $1(2 \%)$ & $3.9 \pm 0.4$ \\
\hline The interpreter helps me only with translation because I do not speak Swedish & 53 & $50(94 \%)$ & $3(6 \%)$ & $3.8 \pm 0.6$ \\
\hline $\begin{array}{l}\text { While I talk through an interpreter it is important to express myself clearly so the interpreter will } \\
\text { be able to support me }\end{array}$ & 52 & $48(91 \%)$ & $4(8 \%)$ & $3.7 \pm 0.7$ \\
\hline A nurse/physician always books an interpreter in advance when I need it & 52 & $47(87 \%)$ & $5(10 \%)$ & $3.5 \pm 0.7$ \\
\hline $\begin{array}{l}\text { It is difficult to guarantee that what I have said during the interpretation is made in confidence } \\
\text { and that the interpreter will not spread it to others }\end{array}$ & 53 & $45(85 \%)$ & $8(15 \%)$ & $3.3 \pm 0.8$ \\
\hline I prefer an interpreter who helps me with transport both before and after consultations in healthcare & 52 & $36(67 \%)$ & $16(15 \%)$ & $3.0 \pm 1.1$ \\
\hline $\begin{array}{l}\text { I always get a feeling of uncertainty while I talk through an interpreter because I do not know } \\
\text { whether what I say is correctly translated or not }\end{array}$ & 53 & $32(60 \%)$ & $21(40 \%)$ & $2.6 \pm 1.1$ \\
\hline I find that talking through an interpreter reduces intimacy between healthcare staff and me & 51 & $30(57 \%)$ & $21(40 \%)$ & $1.9 \pm 1.0$ \\
\hline Talking through an interpreter makes me feel handicapped as I cannot speak Swedish & 53 & $23(43 \%)$ & $30(57 \%)$ & $2.3 \pm 1.2$ \\
\hline I have not been in any situations in healthcare when booked interpreters have not turned up & 51 & $23(43 \%)$ & $28(53 \%)$ & $2.4 \pm 1.2$ \\
\hline $\begin{array}{l}\text { I always get a feeling of uncertainty while I talk through an interpreter because I do not know } \\
\text { whether what I say is correctly translated or not }\end{array}$ & 53 & $15(28 \%)$ & $38(72 \%)$ & $1.9 \pm 1.0$ \\
\hline The interpreter should not interpret literally and objectively & 52 & $12(25 \%)$ & $40(75 \%)$ & $1.7 \pm 1.2$ \\
\hline
\end{tabular}


Table 3 Questions related to the professional and personal qualities of an interpreter in the survey of Arabic-speaking individuals' attitudes to the use of interpreters in healthcare

\begin{tabular}{|c|c|c|c|c|}
\hline Variable & $\mathbf{N}$ & $\begin{array}{l}\text { Agree } \\
\text { N (\%) }\end{array}$ & $\begin{array}{l}\text { Disagree } \\
\mathrm{N}(\%)\end{array}$ & $\begin{array}{l}\text { Mean } \\
\pm \text { Sd. }\end{array}$ \\
\hline It is of no importance whether an interpreter is fluent in both languages & 52 & $51(96 \%)$ & $1(2 \%)$ & $3.9 \pm 0.4$ \\
\hline It is important that an interpreter has a great ability to translate & 52 & $51(96 \%)$ & $1(2 \%)$ & $3.9 \pm 0.3$ \\
\hline An interpreter should show me respect & 53 & $51(96 \%)$ & $2(4 \%)$ & $3.8 \pm 0.5$ \\
\hline $\begin{array}{l}\text { It is important that an interpreter have training both in the language and the terminology } \\
\text { used in healthcare }\end{array}$ & 52 & $50(94 \%)$ & $2(3 \%)$ & $3.9 \pm 0.5$ \\
\hline It is important that the interpreter is neutral and impartial & 51 & $48(91 \%)$ & $3(9 \%)$ & $3.7 \pm 0.6$ \\
\hline The interpreter's age is of no importance for the translation & 52 & $41(77 \%)$ & $11(21 \%)$ & $3.1 \pm 1.0$ \\
\hline It is important that an interpreter talks the same dialect as me & 53 & $40(75 \%)$ & $13(25 \%)$ & $3.3 \pm 1.0$ \\
\hline It is not important what clothes an interpreter wears and whether he/she is provocatively dressed & 52 & $36(68 \%)$ & $16(30 \%)$ & $3.0 \pm 1.3$ \\
\hline It is not important what religion the interpreter belongs to & 53 & $35(66 \%)$ & $18(34 \%)$ & $2.7 \pm 1.2$ \\
\hline It is important that I know what country the interpreter comes from & 53 & $34(64 \%)$ & $19(36 \%)$ & $2.9 \pm 1.2$ \\
\hline I think that it is important to use an interpreter of the same gender as myself & 51 & $31(58 \%)$ & $20(38 \%)$ & $2.8 \pm 1.2$ \\
\hline $\begin{array}{l}\text { It is not important that the interpreter introduces him/herself to me before starting the } \\
\text { interpretation session }\end{array}$ & 53 & $16(30 \%)$ & $37(70 \%)$ & $2.0 \pm 1.2$ \\
\hline It is not important that an interpreter is trained & 52 & $14(26 \%)$ & $38(72 \%)$ & $1.9 \pm 1.1$ \\
\hline $\begin{array}{l}\text { It is of no importance to me whether the interpreter tells other people about what I } \\
\text { have told the physician or nurse during my consultation in which he/she has interpreted }\end{array}$ & 53 & $8(15 \%)$ & $45(85 \%)$ & $1.4 \pm 0.9$ \\
\hline
\end{tabular}

for almost two thirds (66\%). However, knowledge of medical terminology and translation ability were perceived as important for all informants, with few exceptions (94\% and 96\%). It was also important to three quarters of the participants $(75 \%)$ that an interpreter should talk the same dialect as the individual, and having an interpreter trained in the language and having skill in medical terminology was important for most of the participants (83\%).

One of the professional qualities, the education of interpreters, was important for almost three quarters of participants (72\%). Other essential professional qualities included the interpreter showing respect (96\%) for the parties involved in the encounter, introducing themselves (70\%), maintaining the code of confidentiality (85\%) and showing objectivity (91\%).

Nearly two thirds of the participants (64\%), mostly men $(n=21)$, found it important that the patient and the interpreter should share the same origin. More than half of the participants (58\%) thought it essential that the interpreter should be of the same gender as the person needing the interpreter. To feel trust in the interpreters, it was important that an interpreter has similar outfit as the participant for almost half of the respondents (42\%). However, interpreters wearing of non-provocative or neutral clothes and similar clothes to the participants', and their age (with the exception of a few participants (17\%) who felt trust in younger interpreters), were not important to nearly three thirds (68\%) and three quarters $(77 \%)$ of the respondents respectively.

\section{Modes of interpretation and the types of interpreter}

The majority of the respondents (87\%) preferred personal contact with face-to-face interaction with the interpreter, while nearly two thirds (64\%) perceived no differences between face-to-face and telephone interpretation, as the opportunity to follow the interpreter's body language was rated as not important by nearly two thirds of the participants (64\%) (see Table 4). However, most participants (92\%) preferred interpretation by telephone when discussing sensitive matters. The results showed that almost all individuals (98\%) preferred to use a professional interpreter because of their professional training, ensuring high-quality language skills, and being employed by an interpreter agency.

Nearly half of the participants (47\%) wanted to use family members as interpreters. More than half of the respondents (62\%) could see advantages in using family members as interpreters because they also provided support. Half of the participants (53\%) expressed trust in family members as interpreters rather than an unknown interpreter. However, half of the informants (68\%) could see the risk in family members as interpreters, on account of their inability to fully grasp the language.

Concerning the use of bilingual healthcare professionals as interpreters, positive experiences were reported as they gave fast and effective help without delay for the majority of individuals (87\%). However, half of participants (51\%) could see the risk in bilingual healthcare professionals as interpreters, on account of their inability to fully grasp the language. 
Table 4 Questions related to modes of interpretation and the types of interpreter in the survey of Arabic-speaking individuals' attitudes to the use of interpreters in healthcare

\begin{tabular}{|c|c|c|c|c|}
\hline Variable & $\mathbf{N}$ & $\begin{array}{l}\text { Agree } \\
\text { N (\%) }\end{array}$ & $\begin{array}{l}\text { Disagree } \\
\mathrm{N}(\%)\end{array}$ & $\begin{array}{l}\text { Mean } \\
\pm \text { Sd. }\end{array}$ \\
\hline It is good to use an interpreter who has special training and who is employed by an agency & 53 & $52(98 \%)$ & $1(2 \%)$ & $3.8 \pm 0.5$ \\
\hline I prefer to use a telephone interpreter during sensitive investigations & 52 & $49(92 \%)$ & $3(8 \%)$ & $3.7 \pm 0.7$ \\
\hline I prefer to use an interpreter in place & 52 & $46(87 \%)$ & $6(13 \%)$ & $3.3 \pm 0.8$ \\
\hline $\begin{array}{l}\text { Bilingual healthcare staff are good to use as interpreters because they are already in place when } \\
\text { interpreting is to be done }\end{array}$ & 49 & $46(87 \%)$ & $3(13 \%)$ & $3.5 \pm 0.7$ \\
\hline There is no difference between using telephone interpreters and interpreters in place & 52 & $34(64 \%)$ & $18(36 \%)$ & $2.6 \pm 1.1$ \\
\hline $\begin{array}{l}\text { Using a family member/friend as interpreter implies that I get support from family/friend at the } \\
\text { same time as he/she translates }\end{array}$ & 52 & $33(62 \%)$ & $19(38 \%)$ & $2.7 \pm 1.1$ \\
\hline $\begin{array}{l}\text { I feel confidence in using a family member/friend as an interpreter more than an unknown } \\
\text { person being an interpreter }\end{array}$ & 52 & $28(53 \%)$ & $24(47 \%)$ & $2.5 \pm 1.2$ \\
\hline I prefer to use a family member/friend as an interpreter & 53 & $25(47 \%)$ & $28(53 \%)$ & $2.4 \pm 1.1$ \\
\hline There is no risk that all information will not be translated when I use a family member/friend as interpreter & 51 & $17(32 \%)$ & $34(68 \%)$ & $2.0 \pm 1.1$ \\
\hline
\end{tabular}

\section{Discussion}

This study is, to our knowledge, the first study to investigate a non-European migrant group, Arabic-speaking individuals, to elicit their attitudes, opinions, preferences and past experiences concerning the use of interpreters in healthcare. The main study findings document that participants preferred a face-to-face professional interpreter who was an objective aid in communication and practical matters, with a good knowledge of medical terminology, good translation ability and sharing the same origin, dialect and gender as them. This study was an empirical quantitative study that can confirm knowledge from previous qualitative studies of European migrants speaking Bosnian/Croatian/Serbian [10,11,24,29].

A strength of this study could be that the participants were recruited from three different cities in a geographically defined area and healthcare institutions with similar organizations of interpreter services; they differed in age, length of residence in Sweden and educational level. However, they had similar migrational and socioeconomic status, were almost equally divided between genders and born mostly in Iraq. The demographic background in this study ensured a typical picture of the Arabic-speaking population in Sweden [30]. It is difficult to get persons to complete a questionnaire [19], so the response rate (52\%) is fairly good for a questionnaire distributed without reminders being sent.

Developing a new, structured self-administered questionnaire in another language than the author's must be noted as a limitation in this investigation. However, the translation of data was done by a professional translator and then back-translated into Swedish by another professional translator [25]. Finally, the questionnaire was pilot-tested by Arabic-speaking persons for accuracy in the transcriptions; still, the new structured self-administered questionnaire should be translated and developed in other languages to ensure its relevance. The study results strengthen the findings from previous qualitative studies of a different language group. Yet, it would need a further study with a larger sample to be able to generalize the study results.

The preferred mode of interpretation in healthcare encounters was face-to-face interaction with professional interpreters. This outcome supports those of previous qualitative studies from the perspective of Bosnian/Croatian/ Serbian-speaking migrants living in Sweden [24] and Bosnian/Croatian/Serbian- and Russian-speaking migrants living in Ireland [15]. Documented benefits of the use of professional interpreters were that they significantly reduce errors with potential clinical consequences compared to an informal interpreter (family member or bilingual healthcare staff) [31] and the professional interpreter improves communication between patient and healthcare staff [6-8], which leads to better quality of treatment [32].

On the other hand, this study's results are in contrast to those of previous qualitative studies involving mostly Asian-born respondents in the UK who preferred family members as interpreters [16,17]. The differences between the studies can be explained by the dissimilarity in the countries' legal rights to interpreters and in their migration history. First, legislation to enforce support through interpretation is in effect in Sweden [33] but unclear or lacking in other countries including the UK [34]. Previous studies in the UK [35] and the US [36] found that patients were unaware that healthcare staff could access interpreting services for their healthcare consultations. Second, Irish [37] and Swedish [12] migration populations consist mostly of labour migrants and forced migrants, and both Sweden and Ireland lack established migrant communities. In the UK [38], by contrast, there is mostly voluntary migration and the 
country has more established homogeneous migrant communities related to the Commonwealth. However, our findings may be relevant for newly arrived migrants in undeveloped migrant communities in countries that have a clear legal right to interpreters in healthcare encounters.

Confidence between parties in interpreter consultations is essential for effective communication and providing quality care $[39,40]$. This investigation showed that trust in the interpreter was associated with language skill in medical terminology, education, sharing the same dialect, showing respect and objectivity, and keeping the code of confidentiality. The qualities of interpreters discussed by participants were mostly in agreement with what has previously been stated by patients $[16,24]$, healthcare staff [10] and family members [11]. The dissimilarities between studies were revealed in the fact that (i) the interpreter's skill in both languages, (ii) the interpreter's religion, (iii) the interpreter wearing neutral clothes and (iv) being able to follow the interpreter's body language were not important factors for feeling confidence in the process. The dissimilarities and the opinions contradictory to this result might be due either to differences in the method used for investigation or else participants did not properly read the survey/question because the statement was negatively formulated. More studies are needed to investigate whether this may be due to the method of investigation or to the construction of the questionnaires.

A new finding compared to the qualitative studies among European, Bosnian/Croatian/Serbian-speaking, migrants living in Sweden [24] and family members [11] was that the majority of respondents experienced a willingness among healthcare professionals to book an interpreter when needed. One possible explanation for the differences between the studies could be the differences in the methods used. Another possible explanation could be that culture has an impact on how people respond to health and illness, which affects self-care, health-seeking behavior and health [2]. A study investigating beliefs about health, illness and healthcare in female Arabic-speaking migrants with gestational diabetes showed an active informationseeking behavior, in contrast to female Bosnian/Croatian/ Serbian-speaking migrants with diabetes mellitus, who revealed a passive attitude to self-care, relying on healthcare staff for help [41]. In this study Arabic-speaking migrants might be required among healthcare staff to book interpreters, in contrast to Bosnian/Croatian/Serbian-speaking migrants who relied on the willingness of healthcare staff. A third explanation could be either the healthcare staff's attitude to different migrant groups or healthcare staff's increased knowledge and positive attitude over time between studies focusing on the importance of professional interpreters in healthcare encounters. A previous study [42] investigating healthcare professionals' perceptions of beliefs about health and illness in migrants with diabetes mellitus found that a common attitude among healthcare staff to non-European migrants was that there were great dissimilarities in language and culture [42]. However, healthcare staff's attitudes to migrant groups are important to consider in healthcare encounters, which in turn may influence the use of interpreters. The main goal in healthcare is individualized and holistic healthcare based on ideals of equal value and fair and equal treatment for all people [1].

\section{Conclusion}

This investigation corroborated previous qualitative findings from another migrant group with a different cultural and linguistic background. Furthermore, this study confirms the complexity inherent in healthcare interpretation services. Similarities were found in the desire to have a face-to-face professional interpreter who was an objective aid to communication and practical matters, with a good knowledge of medical terminology, good translation ability and sharing the same origin, dialect and gender as them. Attitudes differed as to whether the interpreter should be equally competent in both languages, be of the same religion, wear neutral clothes, and as regards the willingness of healthcare professionals to book an interpreter.

The implication of the study is the importance of planning for the use of interpreters in accordance with the individuals' desire, irrespective of the migrant's linguistic and cultural background. It is also necessary for healthcare staff to put demands on interpreting agencies to offer neutral interpreters highly trained in medical terminology, and with a professional attitude in order to promote the use of interpreters in a healthcare encounter. Further, the use of interpreters in accordance with individuals' desire can prevent and limit poor communication, thereby increasing cost-effective, high-quality individualized healthcare.

\section{Competing interests}

The authors declare that they have no competing interests.

\section{Authors' contributions}

EH was responsible for the study conception and design, development of the questionnaire, carried out the data collection, performed descriptive statistical analyses and drafted and revised the manuscript. BA helped in the descriptive statistical analyses. $\mathrm{BA}$ and $\mathrm{KH}$ helped in the design of the study and coordination. $\mathrm{EH}, \mathrm{BA}$ and $\mathrm{KH}$ performed the drafting of the manuscript. All authors read and approved the final manuscript.

\section{Acknowledgement}

The authors are grateful to Dr Alan Crozier, professional translator, for reviewing the language. This study was performed with grants from the Crafoord Foundation, Sweden.

Received: 5 August 2013 Accepted: 30 January 2014

Published: 3 February 2014 


\section{References}

1. World Health Organization., United Nations. Office of the High Commissioner for Human Rights: Human rights, health, and poverty reduction strategies. Geneva, Switzerland: United Nations Office of the High Commissioner for Human Rights: World Health Organization; 2008.

2. Leininger MM, McFarland MR: Culture care diversity and universality: a worldwide nursing theory, Sudbury, Mass. 2nd edition. London: Jones and Bartlett; 2006.

3. Komaric N, Bedford S, van Driel ML: Two sides of the coin: patient and provider perceptions of health care delivery to patients from culturally and linguistically diverse backgrounds. BMC Health Serv Res 2012, 12(1):322.

4. Divi C, Koss R, Schmaltz S, Loeb J: Language proficiency and adverse events in US hospitals: a pilot study. Int I Qual Health Care 2007, 19(2):60-67.

5. Ramirez D, Engel KG, Tang TS: Language interpreter utilization in the emergency department setting: a clinical review. J Health Care Poor Underserved 2008, 19(2):352-362.

6. Flores $\mathrm{G}$ : The impact of medical interpreter services on the quality of health care: a systematic review. Med Care Res Rev 2005, 62(3):255-299.

7. Karliner L, Jacobs E, Chen A, Mutha S: Do professional interpreters improve clinical care for patients with limited english proficiency? A systematic review of the literature. Health Serv Res 2007, 42(2):727-754

8. Bagchi AD, Dale S, Verbitsky-Savitz N, Andrecheck S, Zavotsky K, Eisenstein R: Examining effectiveness of medical interpreters in emergency departments for Spanish-speaking patients with limited English proficiency: results of a randomized controlled trial. Ann Emerg Med 2011, 57(3):248-256. e241-244.

9. Hadziabdic E: The use of interpreters in healthcare. Perspectives of individuals, healthcare staff and families, PhD thesis. Linnaeus University: School of Health and Caring Sciences; 2011.

10. Hadziabdic E, Albin B, Heikkilä K, Hjelm K: Healthcare staffs perceptions of using interpreters: a qualitative study. Prim Health Care Res Dev 2010, 1(-1):1-11.

11. Hadziabdic E, Albin B, Heikkilä K, Hjelm K: Family members' experiences of using interpreters in healthcare. Prim Health Care Res Dev 2013. doi:10.1017/S1463423612000680.

12. Ekberg J: Invandringen och de offentliga finanserna (Immigration and public finances). Stockholm: Fritzes; 2009.

13. Sverige (Sweden). Statistiska centralbyrån: Tabeller över Sveriges befolkning 2009 (Tables on the population in Sweden 2009). Örebro: Statistiska centralbyrån; 2010.

14. Migration B: Verksamhets- och kostnadsprognos 2013-07-29 (Operational and cost forecast 2013-07-29). http://www.migrationsverket.se/download/ 18.5e83388f141c129ba6312d97/1381926428718/Migrationsverkets+prognos +4\%2813\%29.pdf; 2013 a.

15. MacFarlane A, Dzebisova Z, Karapish D, Kovacevic B, Ogbebor F, Okonkwo E: Arranging and negotiating the use of informal interpreters in general practice consultations: experiences of refugees and asylum seekers in the west of Ireland. Soc Sci Med 2009, 69(2):210-214.

16. Edwards $R$, Temple B, Alexander C: Users' experiences of interpreters: the critical role of trust. Interpreting 2005, 7:77-95.

17. Rhodes P, Nocon A: A problem of communication? Diabetes care among Bangladeshi people in Bradford. Health Soc Care Community 2003, 11(1):45-54.

18. Fatahi N, Nordholm L, Mattsson B, Hellström M: Experiences of Kurdish war-wounded refugees in communication with Swedish authorities through interpreter. Patient Educ Couns 2010, 78(2):160-165.

19. Bowling A: Research methods in health: investigating health and health services. 3rd edition. Maidenhead: McGraw-Hill Open University Press; 2009.

20. Regional statistik (Regional Statistics). [http://www.migrationsinfo.se/ regional-statistik]

21. Förvaltningslag (Managment Act) Justitiedepartementet L6. Stockholm; 1986:223 [http://www.riksdagen.se/sv/Dokument-Lagar/Lagar/Svenskforfattningssamling/ Forvaltningslag-1986223_sfs-1986-223/?bet=1986:223]

22. God tolksed. Vägledning för auktoriserade tolkar (Good interpreting practice. Guidance for authorized interpreters). [http://www. kammarkollegiet.se/sites/default/files/god_tolksed.pdf]

23. Hadziabdic E: The use of interpreter in healthcare: perspectives of individuals, healthcare staff and families. Växjö: Linnaeus University Press Intellecta Infolog); 2011.

24. Hadziabdic E, Heikkila K, Albin B, Hjelm K: Migrants' perceptions of using interpreters in health care. Int Nurs Rev 2009, 56(4):461-469.
25. Maneesriwongul W, Dixon JK: Instrument translation process: a methods review. J Adv Nurs 2004, 48(2):175-186.

26. Graziano AM, Raulin ML: Research methods : a process of inquiry. 8th edition. Boston: Pearson; 2013.

27. SFS: Lag om etikprövning av forskning som avser människor (The Act concerning the Ethical Review of Research Involving Humans). Stockholm: Utbildningsdepartementet; 2003:460.

28. World Medical Association Declaration of Helsinki: Ethical principles for medical research involving human subjects. Nurs Ethics 2002, 9(1):105-109.

29. Hadziabdic E, Heikkila K, Albin B, Hjelm K: Problems and consequences in the use of professional interpreters: qualitative analysis of incidents from primary healthcare. Nurs Inq 2011, 18(3):253-261.

30. Migration till Sverige- bakgrund och fakta (Migration to Sweden- Background and Facts). [http//www.migrationsverket.se/Om-Migrationsverket/Fakta-ommigration/Migration-till-Sverige—-bakgrund-och-fakta/lrakier/rakier-i-Sverige.html]

31. Flores $\mathrm{G}$, Abreu M, Barone CP, Bachur R, Lin H: Errors of medical interpretation and their potential clinical consequences: a comparison of professional versus ad hoc versus no interpreters. Ann Emerg Med 2012, 60(5):545-553.

32. Jimenez N, Moreno G, Leng M, Buchwald D, Morales LS: Patient-reported quality of pain treatment and use of interpreters in spanish-speaking patients hospitalized for obstetric and gynecological care. J Gen Intern Med 2012, 27(12):1602-1608.

33. SFS: Hälso- och sjukvårdslagen (The Swedish Health and Medical Services Act). In SFS. Stockholm: Socialdepartementet; 1982:763.

34. Adams K, Jones D: Should the NHS curb spending on translation services? Brit Med J 2007, 334(7590):398-399.

35. Barron DS, Holterman C, Shipster P, Batson S, Alam M: Seen but not heard: ethnic minorities' views of primary health care interpreting provision: a focus group study. Prim Health Care Res Dev 2010, 11(2):132-141.

36. Grubbs V, Chen AH, Bindman AB, Vittinghoff E, Fernandez A: Effect of awareness of language law on language access in the health care setting. J Gen Intern Med 2006, 21(7):683-688.

37. Ireland: from rapid immigration to recession. [http://www. migrationinformation.org/Feature/display.cfm?ID=740]

38. Cruickshank JK, Beevers DG: Ethnic factors in health and disease. Oxford: Butterworth-Heinemann; 1994.

39. Greenhalgh T, Robb N, Scambler G: Communicative and strategic action in interpreted consultations in primary health care: a Habermasian perspective. Soc Sci Med 2006, 63(5):1170-1187.

40. Robb N, Greenhalgh T: "You have to cover up the words of the doctor": the mediation of trust in interpreted consultations in primary care. $J$ Health Organ Manag 2006, 20(5):434-455.

41. Hjelm K, Bard K, Nyberg P, Apelqvist J: Religious and cultural distance in beliefs about health and illness in women with diabetes mellitus of different origin living in Sweden. Int J Nurs Stud 2003, 40(6):627-643.

42. Hjelm K, Isacsson $\AA$, Apelqvist J: Healthcare professionals' perceptions of beliefs about health and illness in migrants with diabetes mellitus. Pract Diabetes Int 1998, 15(8):233-237.

doi:10.1186/1756-0500-7-71

Cite this article as: Hadziabdic et al: Arabic-speaking migrants' attitudes, opinions, preferences and past experiences concerning the use of interpreters in healthcare: a postal cross-sectional survey. BMC Research Notes 2014 7:71. 